\title{
Association of ACE2 polymorphisms with susceptibility to essential hypertension and dyslipidemia in Xinjiang, China
}

Yizhi Pan ${ }^{1 \dagger}$, Tianyi Wang ${ }^{1 \dagger}$, Yanfang $\mathrm{Li}^{2}$, Tianwang Guan ${ }^{2}$, Yanxian Lai ${ }^{1}$, Yan Shen ${ }^{1}$, Abudurexiti Zeyaweiding ${ }^{3}$, Tutiguli Maimaiti ${ }^{3}$, Fang $\mathrm{Li}^{3}$, Haiyan Zhao $^{3}$ and Cheng Liu ${ }^{1,2,3^{*}}$ (D

\begin{abstract}
Background: Cardiovascular benefits by reversing environmental risks factors for essential hypertension (EH) and dyslipidemia could be weaken by high genetic risk. We investigated possible associations between ACE2 polymorphisms and dyslipidemia in patients with EH.

Methods: Four hundred and two hypertensive patients were enrolled in an EH group and 233 normotensive individuals were enrolled as control group from the Xinjiang region of China. Fourteen ACE2 polymorphisms were genotyped by Matrix-assisted laser desorption ionization time-of-flight mass spectrometry.

Results: Participants carrying T allele $(T+C T)$ of rs2074192 $(P=0.006)$, rs4646155 $(P=0.030)$ and rs4646188 $(P<0$. 001), $C$ allele $(C T+C T$ or $C C+C G)$ of rs4240157 $(P=0.012)$, rs4830542 $(P=0.020)$ and rs879922 $(P<0.001)$ and $T$ genotype of rs2106809 ( $P=0.012$ ) were associated with EH. Meanwhile,ACE2 SNPs also exhibited association with dyslipidemia but exhibited obvious heterogeneity. rs1978124 (TT $+C T, P=0.009)$, rs2106809 (TT, $P=0.045)$, rs 233575 $(C C+C T, P=0.018)$, rs4646188 (CC, $P=0.011)$ and $r 5879922(C C+C G, P=0.003)$ were association with increased LDL-C ( $\geq 1.8 \mathrm{mmol} / \mathrm{L}) . \mathrm{rs} 2106809$ (CC $+C T, P<0.001), \mathrm{rs} 2285666(T \mathrm{~T}+\mathrm{CT}, P=0.017), \mathrm{rs} 4646142(C C+C G, P=0.044)$, rs4646155(TT $+C T, P<0.001)$ and $r s 4646188(T T+C T, P=0.033)$ were association with decreased HDL-C $(<1.0 \mathrm{mmol} /$ L). rs2074192 (TT $+C T, P=0.012), r s 4240157(C C+C T, P=0.027), r s 4646156$ (AA+AT, $P=0.007), r s 4646188(T T+C T, P$ $=0.005)$, rs4830542 $(C C+C T, P=0.047)$ and rs879922 $(C C+C G, P=0.001)$ were association with increased $T C(\geq 5$. $2 \mathrm{mmol} / \mathrm{L})$. rs $2106809(P=0.034)$ and rs4646188 $(P=0.013)$ were associated with hypertriglyceridemia. Further, ischemic stroke was more prevalent with rs4240157 (CC $+C T, P=0.043)$, rs4646188 (CC $+C T, P=0.013$ ) and rs4830542 (CC $+C T, P=0.037$ ). In addition, rs2048683 and rs6632677 were not association with EH, dyslipidemia and ischemic stroke.
\end{abstract}

Conclusion: The ACE2 rs4646188 variant may be a potential and optimal genetic susceptibility marker for EH, dyslipidemia and its related ischemic stroke.

Keywords: Association, ACE2 polymorphism, Essential hypertension, Dyslipidemia, Ischemic stroke

\footnotetext{
* Correspondence: eyliucheng@scut.edu.cn

${ }^{\dagger}$ Yizhi Pan and Tianyi Wang contributed equally to this work.

'Department of Cardiology, Guangzhou First People's Hospital, Medical

School, South China University of Technology, \#1 Panfu road, Guangzhou

510180, China

2Department of Cardiology, Guangzhou First People's Hospital, Guangzhou

Medical University, Guangzhou 510180, China

Full list of author information is available at the end of the article
}

(c) The Author(s). 2018 Open Access This article is distributed under the terms of the Creative Commons Attribution 4.0 International License (http://creativecommons.org/licenses/by/4.0/), which permits unrestricted use, distribution, and reproduction in any medium, provided you give appropriate credit to the original author(s) and the source, provide a link to the Creative Commons license, and indicate if changes were made. The Creative Commons Public Domain Dedication waiver (http://creativecommons.org/publicdomain/zero/1.0/) applies to the data made available in this article, unless otherwise stated. 


\section{Background}

Essential hypertension (EH) is a clinical syndrome characterized by increased systemic arterial pressure ( $\mathrm{SBP} \geq$ $140 \mathrm{mmHg} / \mathrm{DBP} \geq 90 \mathrm{mmHg}$ ) that often leads to dysfunction or damage of organs including the heart, brain and kidney. The incidence of hypertension has steadily increased over the past decade [1], and the proportion of hypertensive patients with other cardiovascular risk factors (e.g., dyslipidemia, overweight/obesity and lack of physical activity, etc) has increased continuously with the increasing prevalence of EH in China [2]. Hypertension plus dyslipidemia is also recognized as the leading cause in global death of vascular disease [3]. Genetic background notwithstanding, comprehensive management of those multiple modifiable risk factors (e.g., unhealthy diet, lack of physical activity, smoking, obesity, and dyslipidemia, etc) is significant associated with lower blood pressure, lower LDL-C and lower cardiovascular events (e.g., arteriosclerosis cardiovascular disease (ASCVD)) [4], but the cardiovascular benefits of healthy lifestyles could be weaken or offset by high genetic risk [5]. Thus, clinical evaluation of genetic background must be considered along with emphasizing the influence of lifestyle modification on the prevention of hypertension, dyslipidemia and its related cardiovascular events [6].

Numerous candidate genes have been implicated in susceptibility to $\mathrm{EH}$. In recent years genes of the renin-angiotensin-aldosterone system (RAAS) have received a good deal of attention. Angiotensin converting enzyme 2 (ACE2) is an important regulator of RAAS (a homolog of $\mathrm{ACE}$ ), and a monocarboxypeptidase that converts angiotensin II (Ang II) into angiotensin 1-7 (Ang 1-7) which, by virtue of its actions on the Mas receptor, negatively regulates Ang II-induced cardiovascular damage, and exhibites notable cardiovascular protective effects [7]. ACE2 maps to chromosome Xp22, spans $39.98 \mathrm{~kb}$ of genomic DNA, and contains 20 introns and 18 exons. The ACE2 gene encodes a type I membrane-bounding glycoprotein composed by 805 amino acids. Functional domains include a C-terminal transmembrane anchoring region, $\mathrm{N}$-terminal signal peptide region and an HEXXH zinc binding metalloprotease motif. ACE2 polymorphisms not only associated with $\mathrm{EH}$ in the Chinese population [8] but also exhibited geographical (southern vs. northern [9-12]), ethnic (Han vs. non-Han nationality) [11-13], and gender (females and males $[9,10])$ diversity. However, the association of ACE2 SNPs with dyslipidemia and ASCVD (e.g., ischemic stroke (IS)) in Xinjiang region of China are rarely reported. Theoretically, there may be common genetic basis between dyslipidemia, hypertension and its related IS $[14,15]$ manifesting the characteristics of ethnic-specific genetic pleiotropy [16]. In this study we investigated possible associations of ACE2 gene variations with hypertension, dyslipidemia and its related cardiovascular events in Xinjiang.

\section{Methods \\ Study participants}

This study was reviewed and approved by the Ethics Committee of Guangzhou First People's Hospital, the Second Affiliated Hospital of South China University of Technology. From August 2012 to December 2017, a total of 402 consecutive patients with EH (222 Han and 180 Uygur) and 233 normotensive subjects (116 Han and 117 Uygur) from the southern Xinjiang, China were enrolled in the study. Both Han and Uygur participants were long resident in the region and were from multi-generation resident families. The newly hypertensive patients were diagnosed according to the criteria of the 1999 World Health Organization/International Society of Hypertension (WHO/ISH) as follows: (1) systolic blood pressure $(\mathrm{SBP}) \geq 140 \mathrm{mmHg}$ and/or diastolic blood pressure (DBP) $\geq 90 \mathrm{mmHg}$; (2) diagnosed as $\mathrm{EH}$ for the first time and did not receive any antihypertensive treatment. Any participants diagnosed with white coat hypertension and secondary hypertension were excluded from the study according to $2013 \mathrm{ESH} / \mathrm{ESC}$ guidelines for the management of arterial hypertension [17]. The normotensive individuals were recruited a medical examination at the same hospital, and were clinically confirmed in the absence of hypertension according to previously described methods with slight modifications [18]. All stroke participants were survivors of ischemic stroke (IS), and diagnosed by computed tomography and/or magnetic resonance image scanning of the brain according to guidelines for prevention of stroke in patients with ischemic stroke or transient ischemic attack [19]. All biochemistry tests were performed by standard methods in the Chemical Laboratory.

\section{Genotyping assay}

Genomic DNA was extracted from whole blood using the Maxwell RSC Whole blood DNA kit (Promega, Madison, WI), quantified using NanoDrop-1000 (ThermoFisher, Waltham, MA) and diluted to $10 \mathrm{ng} / \mu \mathrm{L}$ concentration. Fourteen ACE2 SNPs (rs1978124, rs2048683, rs2074192, rs2106809, rs2285666, rs233575, rs4240157, rs4646142, rs4646155, rs4646156, rs4646188, rs4830542, rs6632677 and rs879922) were identified based on existing literature and human genome sequence databases. Primers for ACE2 SNPs were designed based upon sequence information from GenBank using Primer 5.0 (Whitehead Institute Cambridge, Massachusetts, USA) and Operon's Oligo software 7.60 (OperonTechnologies Inc., Alameda, California, USA). Primers are shown in Additional file 1: Table S1. ACE2 SNPs were analyzed 
using the Sequenom MassARRAY system according to previously described methods [20]. Genotyping accuracy was determined by genotype concordance between duplicate samples and was 100\% for each SNP.

\section{Statistical analysis}

Because ACE2 is located on the X chromosome, HardyWeinberg equilibrium was assessed only for females as shown in Additional file 1: Table S2. Analysis was performed using SPSS version 20 (SPSS, Chicago, IL). Categorical variables (gender, nationality, $\mathrm{EH}$, high low-density lipoprotein cholesterol(LDL-C $\geq 1.8 \mathrm{mmol} / \mathrm{L}$ ), low high-density lipoprotein cholesterol (HDL-C $<1.0 \mathrm{mmol} / \mathrm{L})$, high total cholesterol $(\mathrm{TC} \geq 5.2 \mathrm{mmol} / \mathrm{L}$ ), high triglyceridemia (TRIG $\geq 1.7 \mathrm{mmol} / \mathrm{L}$ ) [21] and IS) were presented as frequencies. The relationship between each ACE2 SNP and those categorical variables were assessed using the Chi square test. The Odds ratio (OR) between control genotype and high hypertensive risk genotype for each ACE2 SNP among categorical variables was evaluated using binary logistic regression. Considering the possible false positive risk to the final result, Bonferroni adjustment was applied to adjust the $p$-value obtained in multi-logit regression. Continuous variables (age, SBP, DBP, BMI and blood biochemical index) were presented as mean \pm SD. Significant differences for continuous variables were analyzed by two/one way ANOVA or independent-sample t-test according to our research design. The least significant difference (LSD) test was further used to assess differences for two subgroups after variance analysis, to show distinct differences with homogeneous variance, while the Games-Howell test was used for heterogeneous variance. A $P$ value less than 0.05 was considered statistically significant. All probabilities are two-tailed.

\section{Result}

Characteristics of the study participants

Among both Han and Uygur participants, hypertensive and normotensive subjects showed significant differences in SBP, DBP, BMI, LDL-C, serum sodium, serum uric acid, HsCRP and the activation of RAAS (all $P<0.05$ ) but not in gender, age, smoking, drinking, TRIG, TC, HDL-C, lipoprotein A, blood glucose, renal function ( $\mathrm{Cr}, \mathrm{BUN})$, liver function (ALT, AST, Alb) and blood electrolytes (calcium, potassium and magnesium) (all $P>0.05$ ) (see Additional file 1: Table S3).

\section{Association of ACE2 SNPs and EH}

As shown in Table 1, ACE2 SNPs rs2074192 $(P=0.006)$, rs2106809 $(P=0.012)$, rs4240157 $(P=0.012), r$ rs4646155 $(P=0.030), \mathrm{rs} 4646188(P<0.001), \mathrm{rs} 4830542(P=0.020)$ and rs879922 $(\mathrm{P}<0.001)$ were significantly associated with $\mathrm{EH}$.

\section{Association of ACE2 SNPs with increased LDL-C ( $\geq$ $1.8 \mathrm{mmol} / \mathrm{L}$ )}

As shown in Table 2, ACE2 SNPs rs1978124 $(P=0.009)$, rs2236306 $(P=0.045)$, rs233575 $(P=0.018)$, rs4646188 $(P=0.011)$ and rs879922 $(P=0.003)$ were associated with high low-density lipoprotein cholesterol.

Table 1 Association of ACE2 SNPS with EH in participants

\begin{tabular}{|c|c|c|c|c|c|}
\hline \multicolumn{2}{|l|}{ ACE2 SNPS } & \multirow{2}{*}{$\begin{array}{l}\text { Normotensive } \\
\text { (N/\%) }\end{array}$} & \multirow{2}{*}{$\begin{array}{l}\text { Hypertensive } \\
\text { (N/\%) }\end{array}$} & \multirow[t]{2}{*}{$\mathrm{OR}(95 \% \mathrm{Cl})^{\mathrm{a}}$} & \multirow[t]{2}{*}{$P$-value ${ }^{a}$} \\
\hline & & & & & \\
\hline \multirow[t]{2}{*}{ rs2074192 } & CC & $118(50.6)$ & $162(40.3)$ & 1.00 & \\
\hline & $T T+C T$ & $115(59.4)$ & 240(59.7) & $1.72(1.17-2.53)$ & 0.006 \\
\hline \multirow[t]{2}{*}{ rs2106809 } & $C C+C T$ & $121(51.9)$ & $175(43.5)$ & 1.00 & \\
\hline & $T T$ & $112(48.1)$ & $227(56.5)$ & $1.71(1.13-2.58)$ & 0.012 \\
\hline \multirow[t]{2}{*}{ rs4240157 } & $C C+C T$ & $43(18.5)$ & $92(22.9)$ & $1.99(1.17-3.41)$ & 0.012 \\
\hline & $T T$ & $190(81.5)$ & $310(77.1)$ & 1.00 & \\
\hline \multirow[t]{2}{*}{ rs4646155 } & CC & $211(90.6)$ & $334(83.1)$ & 1.00 & \\
\hline & $T T+C T$ & $22(9.4)$ & 68 (16.9) & $1.94(1.06-3.54)$ & 0.030 \\
\hline \multirow[t]{2}{*}{ rs4646188 } & $C C$ & $74(31.8)$ & $85(21.1)$ & 1.00 & \\
\hline & $T T+C T$ & 159 (68.2) & 317 (78.9) & $3.25(1.95-5.41)$ & $<0.001$ \\
\hline \multirow[t]{2}{*}{ rs4830542 } & $C C+C T$ & $43(18.5)$ & $90(22.4)$ & $1.88(1.10-3.23)$ & 0.020 \\
\hline & $T T$ & $190(81.5)$ & $312(77.6)$ & 1.00 & \\
\hline \multirow[t]{2}{*}{ rs879922 } & $C C+C G$ & $40(17.2)$ & 131 (32.6) & $4.86(2.74-8.64)$ & $<0.001$ \\
\hline & GG & $193(82.8)$ & $271(67.4)$ & 1.00 & \\
\hline
\end{tabular}

${ }^{a}$ After adjustment for nationality, gender, age, smoking, BMI, TRIG, LDL-C, HDL-C, Lp(a), FBS, UA, HsCRP and Ang II 
Table 2 Association of ACE2 SNPs with increased LDL-C ( $\geq 1.8 \mathrm{mmol} / \mathrm{L})$ in study subjects

\begin{tabular}{|c|c|c|c|c|c|}
\hline \multirow[t]{2}{*}{ ACE2 SNPS } & & \multicolumn{2}{|l|}{ LDL-C (N/\%) } & \multirow[t]{2}{*}{$\mathrm{OR}(95 \% \mathrm{Cl})^{\mathrm{a}}$} & \multirow{2}{*}{$\begin{array}{l}P_{-} \\
\text {value }^{a}\end{array}$} \\
\hline & & $<1.8 \mathrm{mmol} / \mathrm{L}$ & $\geq 1.8 \mathrm{mmol} / \mathrm{L}$ & & \\
\hline \multirow[t]{2}{*}{ rs1978124 } & $C C$ & $122(91.0)$ & $405(80.0)$ & 1.00 & \\
\hline & $T T+C T$ & $12(9.0)$ & $96(19.2)$ & $2.51(1.26-5.01)$ & 0.009 \\
\hline \multirow[t]{2}{*}{ rs2106809 } & $C C+C T$ & $70(52.2)$ & $226(45.1)$ & 1.00 & \\
\hline & TT & $64(47.8)$ & $275(54.9)$ & $1.58(1.01-2.46)$ & 0.045 \\
\hline \multirow[t]{2}{*}{ rs233575 } & $C C+C T$ & $9(6.7)$ & 75 (15.0) & $2.52(1.17-5.44)$ & 0.018 \\
\hline & $T T$ & $125(93.3)$ & $426(85.0)$ & 1.00 & \\
\hline \multirow[t]{2}{*}{ rs4646188 } & $C C$ & $30(22.4)$ & $129(25.7)$ & $1.96(1.16-3.29)$ & 0.011 \\
\hline & $T T+C T$ & $104(77.6)$ & $372(74.3)$ & 1.00 & \\
\hline \multirow[t]{2}{*}{ rs879922 } & $C C+C G$ & $20(14.9)$ & $151(30.1)$ & $2.48(1.35-4.55)$ & 0.003 \\
\hline & $G G$ & $114(85.1)$ & $350(69.9)$ & 1.00 & \\
\hline
\end{tabular}

${ }^{\mathrm{a}} \mathrm{After}$ adjustment for nationality, gender, age, BMI, EH, FBS, HsCRP and Ang II

\section{Association of ACE2 SNPs with decreased HDL-C $(<$ $1.0 \mathrm{mmol} / \mathrm{L}$ )}

As shown in Table 3, ACE2 SNPs rs2106809 $(P<0.001)$, rs2285666 $(P=0.017)$, rs4646142 $(P=0.044)$, rs4646155 $(P<0.001)$ and rs4646188 $(P=0.033)$ were significantly associated with low high-density lipoprotein cholesterol.

\section{Association of ACE2 SNPs with increased TC $(\geq 5.2 \mathrm{mmol} /$} L)

As shown in Table 4, ACE2 SNPs rs2074192 $(P=0.012)$, rs4240157 $(P=0.027)$, rs4646156 $(P=0.007)$, rs4646188 $(P=0.005)$, rs4830542 $(P=0.047)$ and $\operatorname{rs} 879922(P=$ $0.001)$ were associated with high TC.

\section{Association of ACE2 SNPs with increased TRIG ( $\geq 1.7 \mathrm{mmol} / \mathrm{L}$ )}

As shown in Table 5, ACE2 SNPs rs2106809 $(P=0.034)$ and rs4646188 $(P=0.013)$ were associated with hypertriglyceridemia.

\section{Association of ACE2 SNPs with ischemic stroke}

As shown in Table 6, ACE2 SNPs rs4240157 $(P=0.043)$, rs4646188 $(P=0.013)$ and $\operatorname{rs} 4830542(P=0.037)$ were associated with ischemic stroke.

\section{Discussion}

$\mathrm{EH}$ and dyslipidemia is rapidly developing into an epidemic, and dramatically increases the global cardiovascular events that have become a serious public health problem especially in developing countries (e.g., China) [2], which has become the leading cause of ASCVD-related death (e.g., IS) during the last decade in China [22]. The treatment and prevention outlook for $\mathrm{EH}$ and dyslipidemia is more severe in China [23], especially in minority areas (e.g., Xinjiang) owing to the prevalence of $\mathrm{EH}$ and dyslipidemia differs among different geographic areas (urban and rural) and ethnicities (Han and non-Han (e.g., Uygur) populations) while at the same time $\mathrm{EH}$ and dyslipidemia related stroke is extremely high $[16,24]$. Thus, early identification and

Table 3 Association of ACE2 SNPs with decreased HDL-C (< $1.0 \mathrm{mmol} / \mathrm{L})$ in study subjects

\begin{tabular}{|c|c|c|c|c|c|}
\hline \multirow[t]{2}{*}{ ACE2 SNPS } & & \multicolumn{2}{|l|}{ HDL-C (N/\%) } & \multirow[t]{2}{*}{$\mathrm{OR}(95 \% \mathrm{Cl})^{\mathrm{a}}$} & \multirow[t]{2}{*}{$P$-value ${ }^{a}$} \\
\hline & & $\geq 1.0 \mathrm{mmol} / \mathrm{L}$ & $<1.0 \mathrm{mmol} / \mathrm{L}$ & & \\
\hline \multirow[t]{2}{*}{ rs2106809 } & $C C+C T$ & $215(42.1)$ & $81(65.3)$ & $2.49(1.58-3.91)$ & $<0.001$ \\
\hline & $T T$ & $296(57.9)$ & $43(34.7)$ & 1.00 & \\
\hline \multirow[t]{2}{*}{ rs2285666 } & CC & $194(38.0)$ & 37 (29.8) & 1.00 & \\
\hline & $T T+C T$ & $317(62.0)$ & $87(70.2)$ & $1.73(1.10-2.71)$ & 0.017 \\
\hline \multirow[t]{2}{*}{ rs 4646142} & $C C+C G$ & $318(62.2)$ & $85(68.5)$ & $1.58(1.01-2.46)$ & 0.044 \\
\hline & $G G$ & $193(37.8)$ & $39(31.5)$ & 1.00 & \\
\hline \multirow[t]{2}{*}{ rs4646155 } & CC & 453 (88.6) & $92(74.2)$ & 1.00 & \\
\hline & $T T+C T$ & $58(11.4)$ & $32(25.8)$ & $2.85(1.71-4.75)$ & $<0.001$ \\
\hline \multirow[t]{2}{*}{ rs4646188 } & CC & $123(24.1)$ & $36(29.0)$ & 1.00 & \\
\hline & $T T+C T$ & $388(75.9)$ & $88(71.0)$ & $1.88(1.05-3.35)$ & 0.033 \\
\hline
\end{tabular}

${ }^{a}$ After adjustment for nationality, gender, age, BMI, EH, FBS, HsCRP and Ang II 
Table 4 Association of ACE2 SNPs with increased TC ( $\geq 5.2 \mathrm{mmol} / \mathrm{L})$ in study subjects

\begin{tabular}{|c|c|c|c|c|c|}
\hline \multirow[t]{2}{*}{ ACE2 SNPS } & & \multicolumn{2}{|l|}{ TC (N/\%) } & \multirow[t]{2}{*}{$\mathrm{OR}(95 \% \mathrm{Cl})^{\mathrm{a}}$} & \multirow[t]{2}{*}{$P$-value } \\
\hline & & $<5.2 \mathrm{mmol} / \mathrm{L}$ & $\geq 5.2 \mathrm{mmol} / \mathrm{L}$ & & \\
\hline \multirow[t]{2}{*}{ rs2074192 } & $C C$ & $240(46.0)$ & $40(35.4)$ & 1.00 & \\
\hline & $T T+C T$ & $282(54.0)$ & $73(64.6)$ & $1.83(1.14-2.94)$ & 0.012 \\
\hline \multirow[t]{2}{*}{ rs4240157 } & $C C+C T$ & 102 (19.5) & $33(29.2)$ & $1.78(1.07-2.98)$ & 0.027 \\
\hline & $T T$ & $420(80.5)$ & $80(70.8)$ & 1.00 & \\
\hline \multirow[t]{2}{*}{ rs4646156 } & $A A+A T$ & $57(10.9)$ & 21 (18.6) & $2.34(1.07-4.32)$ & 0.007 \\
\hline & $T T$ & $465(89.1)$ & $92(81.4)$ & 1.00 & \\
\hline \multirow[t]{2}{*}{ rs4646188 } & CC & $143(27.4)$ & $16(14.2)$ & 1.00 & \\
\hline & $T T+C T$ & 379 (72.6) & 97 (85.8) & $2.31(1.29-4.13)$ & 0.005 \\
\hline \multirow[t]{2}{*}{ rs4830542 } & $C C+C T$ & $100(19.2)$ & $33(29.2)$ & $1.64(1.01-2.66)$ & 0.047 \\
\hline & $G T$ & $422(80.8)$ & $80(70.8)$ & 1.00 & \\
\hline \multirow[t]{2}{*}{ rs879922 } & $C C+C G$ & 123 (23.6) & $48(42.5)$ & $2.17(1.38-3.41)$ & 0.001 \\
\hline & GG & $399(76.4)$ & $65(57.5)$ & 1.00 & \\
\hline
\end{tabular}

${ }^{\mathrm{a}}$ After adjustment for nationality, gender, age, BMI, EH, FBS, HsCRP and Ang II

assessing populations at high risk of $\mathrm{EH}$ and dyslipidemia are the key steps in ASCVD (e.g., IS) prevention and control.

This study addressed possible relationships of ACE2 polymorphisms with $\mathrm{EH}$ and dyslipidemia in south Xinjiang region of China. We found that the genotypes of rs2074192 (TT $+\mathrm{CT})$, rs2106809 (TT), rs4240157 $(\mathrm{CC}+\mathrm{CT}), \mathrm{rs} 4646155(\mathrm{TT}+\mathrm{CT})$ and rs4830542 $(\mathrm{CC}+$ $\mathrm{CT})$ were linked to moderate $\mathrm{EH}$ risk $(\mathrm{OR}=1.71-1.99)$ while rs4646188 (TT + CT) and rs879922 (CC + CG) linked to high $\mathrm{EH}$ risk $(\mathrm{OR}=3.25-4.86)$. Our findings are consistent with the observation by Patel et al. [25] who reported ACE2 SNPs (rs2074192, rs4240157 and rs4646188) were associated with higher hypertension risk while rs1978124 was not in a diabetic Australian Caucasian population, and the study by Benjafield et al. [26] who reported that rs1978124 was not correlated with $\mathrm{EH}$ in Australian persons of Anglo-Celtic descent. In this study we newly found rs4646155 and rs879922 were association with $\mathrm{EH}$, but our results are in contrast to the observations by Niu W et al. [9]. The association of ACE2 SNP rs2285666 with hypertension exhibit high genetic heterogeneity and varies with geographical, ethnic and gender [27], this loci was not linked to hypertension in Xinjiang, which was consistent with previously reported the association in northwestern [11] and central [12] China. In addition, this is the first report showing that SNP rs4830542 was associated with $\mathrm{EH}$ while rs2048683 was not correlated with EH (see Additional file 1: Table S4).

Dyslipidemia is the second leading cause of cardiovascular disease-related death after hypertension [23]. The prevalence of hypertension plus dyslipidemia and overweight/obesity was reportedly high in Xinjiang [16, 28] and we made similar observations in the course of this study. Indeed, we also observed that the levels of BMI and LDL-C in hypertensive patients were close to levels of hypertensive patients in the United States [29]. To the best of our knowledge, this is the first more comprehensive study to investigate the association of ACE2 gene polymorphism with dyslipidemia. In previous studies SNP rs2285666 was not linked to dyslipidemia, but its relationship with various subtypes of dyslipidemia is not shown [30]. In this study we found that 9 ACE2 polymorphic loci were respectively correlated with only one type of dyslipidemia, including higher LDL-C (rs1978124 and rs233575), lower HDL-C (rs2285666, rs4646142 and rs4646155) and higher TC (rs2074192, rs4240157, rs4646156 and rs4830542). ACE2 SNP rs879922 (LDL-C and TC), rs2106809 (LDL-C, HDL-C and TRIG) and

Table 5 Association of ACE2 SNPs with increased TRIG ( $\geq 1.7 \mathrm{mmol} / \mathrm{L})$ in study subjects

\begin{tabular}{|c|c|c|c|c|c|}
\hline \multirow[t]{2}{*}{ ACE2 SNPS } & & \multicolumn{2}{|l|}{ TRIG (N/\%) } & \multirow[t]{2}{*}{$\mathrm{OR}(95 \% \mathrm{Cl})^{\mathrm{a}}$} & \multirow[t]{2}{*}{$P$-value } \\
\hline & & $<1.7 \mathrm{mmol} / \mathrm{L}$ & $\geq 1.7 \mathrm{mmol} / \mathrm{L}$ & & \\
\hline \multirow[t]{2}{*}{ rs2106809 } & $C C+C T$ & $229(45.6)$ & $67(50.4)$ & $1.61(1.04-2.49)$ & 0.034 \\
\hline & $T T$ & $273(54.4)$ & $66(49.6)$ & 1.00 & \\
\hline \multirow[t]{2}{*}{ rs4646188 } & $C C$ & $120(23.9)$ & $39(29.3)$ & $1.80(1.13-2.85)$ & 0.013 \\
\hline & $T T+C T$ & $382(76.1)$ & $94(70.7)$ & 1.00 & \\
\hline
\end{tabular}

${ }^{\mathrm{a}}$ After adjustment for nationality, gender, age, BMI, EH, FBS, HsCRP and Ang II 
Table 6 Association of ACE2 SNPs with ischemic stroke in study subjects

\begin{tabular}{llllll}
\hline ACE2 SNPS & & $\begin{array}{l}\text { Non-IS } \\
(\mathrm{N} / \%)\end{array}$ & IS & OR(95\%Cl $)^{\mathrm{a}}$ & $P_{\text {-value }}$ \\
& & $(\mathrm{N} / \%)$ & & \\
\hline rs4240157 & $C C+C T$ & $114(20.2)$ & $21(30.0)$ & $2.18(1.03-4.65)$ & 0.043 \\
& $T T$ & $451(79.8)$ & $49(70.0)$ & 1.00 & \\
rs4646188 & $C C+C T$ & $135(23.9)$ & $24(34.3)$ & $2.44(1.21-4.91)$ & 0.013 \\
& $T T$ & $430(76.1)$ & $46(65.7)$ & 1.00 & \\
rs4830542 & $C C+C T$ & $112(19.8)$ & $21(30.0)$ & $2.25(1.05-4.80)$ & 0.037 \\
& $T T$ & $453(80.2)$ & $49(70.0)$ & 1.00 &
\end{tabular}

${ }^{a}$ After adjustment for nationality, gender, age, smoking, BMI, SBP, DBP, LDL-C, HDL-C, FBS, HsCRP and Ang II

rs4646188 (LDL-C, HDL-C, TC and TRIG) were correlated with more than 2 types of dyslipidemia. However, 2 ACE2 polymorphic loci (rs2048683 and rs6632677) were non-correlated with any type of dyslipidemia (see Additional file 1: Table S5-S8). Not all dyslipidemia risk related ACE2 variation was also associated with hypertension (e.g., rs1978124, rs2285666, rs233575, rs4646142 and rs4646156), but all 7 EH risk related variation were also significantly correlated with dyslipidemia. Almost all high hypertensive risk genotypes of all $\mathrm{EH}$ risk related variations exhibited association with moderate to high risk of dyslipidemia except rs2106809 and rs4646188. Particularly, patients carrying the high EH risk genotype (TT) of rs2106809 were associated with increased LDL-C but those carrying the control genotype $(C C+\mathrm{TT})$ of this loci was associated with decreased HDL-C and hypertriglyceridemia. By contrast, patients carrying the control genotype (CC) of rs4646188 were associated with increased LDL-C and TRIG but those carrying high EH risk genotype (TT + CT) of this loci was associated with the other two types of dyslipidemia. ACE2 polymorphisms correlations with elevated risk of dyslipidemia were obvious heterogeneity in Xinjiang.

Both hypertension and dyslipidemia are clinical risk factors for ASCVD, and the risk for ASCVD increases following the increase in blood pressure and blood lipid level [31]. In this study we found that 3 ACE2 SNPs (rs1978124, rs2074192 and rs879922) were linked to moderate and high risk of $\mathrm{EH}$ or dyslipidemia (increased LDL-C and TC), which previously reported that the three loci were associated with cardiovascular death [32], suggesting that there is a common genetic basis for hypertension, dyslipidemia and cardiovascular events $[33,34]$. Despite EH patients with dyslipidemia received standard hypotensive therapy and lipid-lowering therapy, there is still a significant increase residual risk of ASCVD, that is related to atherogenic dyslipidemia (high TRIG and low HDL-C level) [35]. Our results showed that 2 SNPs (rs2285666 and rs4646142) was not associated with EH (see Additional file 1: Table S4) but exhibited association with decreased HDL-C, which were consistent with previously reported association of the two loci with ASCVD (e.g., coronary heart disease [36], IS [37]). In this study we newly found that ACE2 SNPs rs4646188 were not only correlated with hypertension and atherogenic dyslipidemia but also linked to high risk of ischemic stroke. Four ACE2 SNPs (rs2074192, rs4240157, rs4830542 and rs879922) were association with hypertension and increased TC, but only rs4240157 and rs4830542 also exhibited association with high stroke risk in our study. Meanwhile, we found that rs2074192 and rs879922 were not only non-correlated with IS but also had nothing to do with the recurrence risk of stroke [38]. Although rs6632677 was not associated with hypertension, dyslipidemia and stroke, it was found to be related to left ventricular remodeling [39] and possible atrial fibrillation risk in Chinese population [40]. However, association of SNP rs2048683 with hypertension, dyslipidemia and stroke had been pretty "silent", suggesting that the loci were not protective factors but they are at least not a harmful factor on $\mathrm{EH}$ and $\mathrm{EH}$ related cardiovascular events.

Indeed, the RAAS activation plays a key role in the occurrence and progression of hypertension, dyslipidemia and its related ASCVD (e.g., IS). The circulation and tissue RAAS of hypertension with dyslipidemia are excessively activated [41], which promotes the accumulation of ox-LDL in the blood vessels and further accelerates the process of atherosclerosis. On the other hand, disequilibrium of vascular lipid homeostasis (especially the accumulation of ox-LDL) enhances the activation of RAAS [42]. ACE2 is an essential regulator by antagonizing Ang II mediated cardiovascular injury. Although the roles of ACE2 gene polymorphisms (mutations or variants) on hypertension, dyslipidemia and its related ASCVD were incompletely understood, it may be related to the cross-talk between ACE2/Ang-(1-7)/Mas axis and ACE/Ang II/AT1 axis [43]. ACE2 gene polymorphisms (e.g., rs2106809 [44], rs2074192 [43]) were associated with downregulation of circulating Ang-(1-7). The deletion of ACE2 in mice model was associated with increased circulation and tissue Ang II levels [45], led to cardiovascular damage [46]. The possible mechanism would be related to changes in quantity and function of ACE2 mutant protein owing to ACE2 polymorphism related amino acid substitutions(e.g., 1075A/G(rs1978124), 8790G/A (rs2285666) and 16854G/C(rs4646142), etc. $[25,47])$, which might be involved in the posttranscriptional regulation via microRNA, the mRNA splicing efficiency (e.g., intron splicing enhancer or silencer element) and mRNA stability (e.g., conformation) of ACE2, at least partly confirmed by recent research that the changes of ACE2 expression was in protein level 
rather than mRNA level in mice [48], and microRNA might regulate RAAS activity via by altering the interaction between microRNA and mRNA of targeted gene [44]. In addition, ACE2 SNP rs4830542 was found to be located in the 3'-UTR region while the other 13 ACE2 SNPs (e.g., rs4646188) were in intron. Regardless of those SNPs were in 3'UTR region or intron (both in noncoding region of ACE2 gene), it is still unknown which SNPs is the functional SNP. Potentially, ACE2 SNP rs4646188 is hopeful to be the functional SNP because it is located in a splicing site of ACE2 gene that needs to be investigated further.

Some limitations should be mentioned. First, since our sample size is not large enough, further prospective large sample studies are needed to validate our findings. Secondly, the possibility of false-positive findings should be considered especially for secondary study based on our results.

\section{Conclusion}

ACE2 SNP rs4646188 may be a potential and optimal genetic susceptibility marker for hypertension, dyslipidemia and its related cardiovascular events (i.e., ischemic stroke). Specially, our data showed for the first time that the ACE2 SNP rs4830542 was associated with hypertension and dyslipidemia. Our observations further support that the genetic predisposition of ACE2 SNPs associated with the risk of $\mathrm{EH}$, dyslipidemia and its related cardiovascular events should need large-scale evaluation as well as in different ethnic groups.

\section{Additional file}

Additional file 1: Table S1. ACE2 SNP primers used in the Sequenom MassARRAY system. Table S2. Descriptive information on ACE2 SNPs in study participants. Table S3. Baseline characteristics of study participants. Table S4. Association of 7 ACE2 SNPs with EH in participants. Table S5. Association of ACE2 SNPs with increased LDL-C $(\geq 1.8 \mathrm{mmol} / \mathrm{L})$ in study subjects Table S6 Association of ACE2 SNPs with decreased HDL-C $(<1.0 \mathrm{mmol} /$ $\mathrm{L}$ ) in study subjects. Table S7. Association of ACE2 SNPs with increased TC ( $\geq 5.2 \mathrm{mmol} / \mathrm{L}$ ) in study subjects. Table $\mathbf{S 8}$. Association of ACE2 SNPs with increased TRIG ( $\geq 1.7 \mathrm{mmol} / \mathrm{L})$ in study subjects. (DOCX $84 \mathrm{~kb}$ )

\section{Abbreviation}

ACE2: Angiotensin converting enzyme 2; Alb: Albumin; ALD: Aldosterone; ALT: Alanine aminotransferase; Ang I/ II: Angiotensin I/ll; ASCVD: Arteriosclerosis cardiovascular disease; AST: Aspartate aminotransferase; BMI: Body mass index; BUN: Blood urea nitrogen; Cr: Creatinine; DBP: Diastolic blood pressure; EH: Essential hypertension; FBG: Fasting blood glucose; HbA1C: Glycosylated hemoglobin; HDL-C: Highdensity lipoprotein cholesterol; HsCRP: High-sensitivity C-reactive protein; IS: Ischemic stroke; LDL-C: Low-density lipoprotein cholesterol; Lp(a): Lipoprotein A; LVEF: Left ventricular ejection fraction; LVMI: Left ventricular mass index; MAF: Linor allele frequency; MAU: Licroalbuminuria; RAAS: Renin-angiotensin-aldosterone system; SBP: Systolic blood pressure; SNP: Single nucleotide polymorphism; T2D: Type 2 diabetes mellitus: TC: Total cholesterol; TRIG: Triglyceridemia; UA: Blood uric acid

\section{Acknowledgements}

We thank Prof. Pingsheng Wu for excellent academic assistance, Prof. Fangyao Chen for statistical analysis assistance.

\section{Funding}

This study was supported by grants from the Project of Natural Science Foundation of XUAR, China (NQ. 201318101-12) and the Science and Technology Planning Project of Guangdong Province, China (NQ. 2014A020212372)

\section{Availability of data and materials}

The datasets used and/or analysed during the current study are available from the corresponding author on reasonable request.

\section{Authors' contributions}

TYW and CL, literature search, study format, writing protocol, collecting data, processing data, data interpretation, analysing data, writing manuscript; YZP, YFL and TWG, literature search, study format, writing protocol, recruiting patients and data interpretation; YXL and YS, carring out the molecular genetics; $T M$ and $A Z$, recruiting patients and collecting data; $F L$ and $H Y Z$, recruiting patients, following up patients, collecting data. All authors read and approved the final manuscript.

Ethics approval and consent to participate

Ethics approval was obtained from the institutional review board (2014SYYLSZ-018).

\section{Consent for publication}

Not applicable.

\section{Competing interests}

The authors declare that they have no competing interests.

\section{Publisher's Note}

Springer Nature remains neutral with regard to jurisdictional claims in published maps and institutional affiliations.

\section{Author details}

'Department of Cardiology, Guangzhou First People's Hospital, Medical School, South China University of Technology, \#1 Panfu road, Guangzhou 510180, China. ${ }^{2}$ Department of Cardiology, Guangzhou First People's Hospital, Guangzhou Medical University, Guangzhou 510180, China. ${ }^{3}$ Department of Cardiology, Shufu People's Hospital, Kashgar region 844100, Xinjiang Uygur Autonomous Region (XUAR), China.

Received: 22 August 2018 Accepted: 7 October 2018

Published online: 20 October 2018

\section{References}

1. Wang Z, Chen Z, Zhang L, Wang X, Hao G, Zhang Z, Shao L, Tian Y, Dong Y, Zheng $C$, et al. Status of hypertension in China: results from the China hypertension survey, 2012-2015. In: Circulation; 2018. https://doi.org/10. 1161/CIRCULATIONAHA.117.032380

2. Lewington S, Lacey B, Clarke R, Guo Y, Kong XL, Yang L, Chen Y, Bian Z, Chen J, Meng J, et al. The burden of hypertension and associated risk for cardiovascular mortality in China. JAMA Intern Med. 2016;176:524-32.

3. Lozano R, Naghavi M, Foreman K, Lim S, Shibuya K, Aboyans V, Abraham J, Adair T, Aggarwal R, Ahn SY, et al. Global and regional mortality from 235 causes of death for 20 age groups in 1990 and 2010: a systematic analysis for the global burden of disease study 2010. Lancet. 2012;380:2095-128.

4. Colpani V, Baena CP, Jaspers L, van Dijk GM, Farajzadegan Z, Dhana K, Tielemans MJ, Voortman T, Freak-Poli R, Veloso GGV, et al. Lifestyle factors, cardiovascular disease and all-cause mortality in middle-aged and elderly women: a systematic review and meta-analysis. Eur J Epidemiol. 2018.

5. Pazoki R, Dehghan A, Evangelou E, Warren H, Gao H, Caulfield M, Elliott P, Tzoulaki I. Genetic predisposition to high blood pressure and lifestyle factors: associations with midlife blood pressure levels and cardiovascular events. Circulation. 2018;137:653-61.

6. Luft FC. Geneticism of essential hypertension. Hypertension. 2004;43:1155-9. 
7. Jiang F, Yang J, Zhang Y, Dong M, Wang S, Zhang Q, Liu FF, Zhang K, Zhang $C$. Angiotensin-converting enzyme 2 and angiotensin 1-7: novel therapeutic targets. Nat Rev Cardiol. 2014;11:413-26.

8. Velkoska E, Patel SK, Burrell LM. Angiotensin converting enzyme 2 and diminazene: role in cardiovascular and blood pressure regulation. Curr Opin Nephrol Hypertens. 2016;25:384-95.

9. Niu W, Qi Y, Hou S, Zhou W, Qiu C. Correlation of angiotensin-converting enzyme 2 gene polymorphisms with stage 2 hypertension in Han Chinese. Transl Res. 2007;150:374-80.

10. Chen YY, Liu D, Zhang P, Zhong JC, Zhang CJ, Wu SL, Zhang YQ, Liu GZ, He M, Jin $L$, Yu HM. Impact of ACE2 gene polymorphism on antihypertensive efficacy of ACE inhibitors. J Hum Hypertens. 2016;30:766-71.

11. Yi L, Gu YH, Wang XL, An LZ, Xie XD, Shao W, Ma LY, Fang JR, An YD, Wang F, Zhang DL. Association of ACE, ACE2 and UTS2 polymorphisms with essential hypertension in Han and Dongxiang populations from NorthWestern China. J Int Med Res. 2006;34:272-83.

12. Fan $X H$, Wang $Y B$, Wang $H$, Sun $K$, Zhang $W L$, Song $X D$, Cheng JZ, Wu HY, Zhou XL, Hui RT. Polymorphisms of angiotensin-converting enzyme (ACE) and ACE2 are not associated with orthostatic blood pressure dysregulation in hypertensive patients. Acta Pharmacol Sin. 2009;30:1237-44.

13. Lu N, Yang Y, Wang Y, Liu Y, Fu G, Chen D, Dai H, Fan X, Hui R, Zheng Y. ACE2 gene polymorphism and essential hypertension: an updated metaanalysis involving 11,051 subjects. Mol Biol Rep. 2012;39:6581-9.

14. Kullo IJ, de Andrade M, Boerwinkle E, McConnell JP, Kardia SL, Turner ST. Pleiotropic genetic effects contribute to the correlation between HDL cholesterol, triglycerides, and LDL particle size in hypertensive sibships. Am J Hypertens. 2005;18:99-103.

15. Williams RR, Hunt SC, Hopkins PN, Wu LL, Hasstedt SJ, Berry TD, Barlow GK, Stults BM, Schumacher MC, Ludwig EH, et al. Genetic basis of familial dyslipidemia and hypertension: 15-year results from Utah. Am J Hypertens. 1993;6:3195-27S

16. Tao J, Ma YT, Xiang Y, Xie X, Yang YN, Li XM, Fu ZY, Ma X, Liu F, Chen BD, et al. Prevalence of major cardiovascular risk factors and adverse risk profiles among three ethnic groups in the Xinjiang Uygur autonomous region, China. Lipids Health Dis. 2013;12:185.

17. Carey RM, Whelton PK, Committee AAHGW. Prevention, Detection, Evaluation, and Management of High Blood Pressure in Adults: Synopsis of the 2017 American College of Cardiology/American Heart Association hypertension guideline. Ann Intern Med. 2018(168):351-8

18. Zhou YF, Yan H, Hou XP, Miao JL, Zhang J, Yin QX, Li JJ, Zhang XY, Li YY, Luo HL. Association study of angiotensin converting enzyme gene polymorphism with elderly diabetic hypertension and lipids levels. Lipids Health Dis. 2013;12:187.

19. Kernan WN, Ovbiagele B, Black HR, Bravata DM, Chimowitz MI, Ezekowitz MD, Fang MC, Fisher M, Furie KL, Heck DV, et al. Guidelines for the prevention of stroke in patients with stroke and transient ischemic attack: a guideline for healthcare professionals from the American Heart Association/ American Stroke Association. Stroke. 2014;45:2160-236.

20. Bundock PC, Eliott FG, Ablett G, Benson AD, Casu RE, Aitken KS, Henry RJ. Targeted single nucleotide polymorphism (SNP) discovery in a highly polyploid plant species using 454 sequencing. Plant Biotechnol J. 2009;7:347-54.

21. Catapano AL, Graham I, De Backer G, Wiklund O, Chapman MJ, Drexel H, Hoes AW, Jennings CS, Landmesser U, Pedersen TR, et al. 2016 ESC/EAS guidelines for the Management of Dyslipidaemias. Eur Heart J. 2016;37:2999-3058.

22. Li Q, Wu H, Yue W, Dai Q, Liang H, Bian H, Xia X, Ji Q, Shen Y. Prevalence of stroke and vascular risk factors in China: a Nationwide Community-based study. Sci Rep. 2017;7:6402.

23. Collaborators GBDCoD. Global, regional, and national age-sex specific mortality for 264 causes of death, 1980-2016: a systematic analysis for the global burden of disease study 2016. Lancet. 2017;390:1151-210.

24. Wang $Y$, Zhang J, Ding Y, Zhang M, Liu J, Ma J, Guo H, Yan Y, He J, Wang K, et al. Prevalence of hypertension among adults in remote rural areas of Xinjiang, China. Int J Environ Res Public Health. 2016;13. https://doi.org/10. 3390/ijerph13060524.

25. Patel SK, Wai B, Ord M, Maclsaac RJ, Grant S, Velkoska E, Panagiotopoulos S, Jerums G, Srivastava PM, Burrell LM. Association of ACE2 genetic variants with blood pressure, left ventricular mass, and cardiac function in Caucasians with type 2 diabetes. Am J Hypertens. 2012;25:216-22.

26. Benjafield AV, Wang WY, Morris BJ. No association of angiotensin-converting enzyme 2 gene (ACE2) polymorphisms with essential hypertension. Am J Hypertens. 2004;17:624-8.
27. Ji LD, Li JY, Yao BB, Cai XB, Shen QJ, Xu J. Are genetic polymorphisms in the renin-angiotensin-aldosterone system associated with essential hypertension? Evidence from genome-wide association studies. J Hum Hypertens. 2017:31:695-8.

28. Abudoukelimu M, Fu ZY, Maimaiti A, Ma YT, Abudu M, Zhu Q, Adi D, Yang YN, Li XM, Xie X, et al. The association of cholesterol absorption gene numb polymorphism with coronary artery disease among Han Chinese and Uighur Chinese in Xinjiang, China. Lipids Health Dis. 2015;14:120.

29. Lu Y, Wang P, Zhou T, Lu J, Spatz ES, Nasir K, Jiang L, Krumholz HM Comparison of prevalence, awareness, treatment, and control of cardiovascular risk factors in China and the United States. J Am Heart Assoc. 2018;7. https://doi.org/10.1161/JAHA.117.007462

30. Xu Y, Bao Q, He B, Pan Y, Zhang R, Mao X, Tang Z, Qu L, Zhu C, Tian F, Wang S. Association of angiotensin I converting enzyme, angiotensin II type 1 receptor and angiotensin I converting enzyme 2 gene polymorphisms with the dyslipidemia in type 2 diabetic patients of Chinese Han origin. J Endocrinol Investig. 2012;35:378-83.

31. Wang YX, Song L, Xing AJ, Gao M, Zhao HY, Li CH, Zhao HL, Chen SH, Lu CZ, Wu SL. Predictive value of cumulative blood pressure for all-cause mortality and cardiovascular events. Sci Rep. 2017;7:41969.

32. Sotoodehnia N, Li G, Johnson CO, Lemaitre RN, Rice KM, Rea TD, Siscovick DS. Genetic variation in angiotensin-converting enzyme-related pathways associated with sudden cardiac arrest risk. Heart Rhythm. 2009;6:1306-14.

33. Ference BA, Ginsberg HN, Graham I, Ray KK, Packard CJ, Bruckert E, Hegele RA, Krauss RM, Raal FJ, Schunkert H, et al. Low-density lipoproteins cause atherosclerotic cardiovascular disease. 1. Evidence from genetic, epidemiologic, and clinical studies. A consensus statement from the European atherosclerosis society consensus panel. Eur Heart J. 2017;38: 2459-72.

34. Kullo IJ, Leeper NJ. The genetic basis of peripheral arterial disease: current knowledge, challenges, and future directions. Circ Res. 2015;116:1551-60.

35. Chawla A, Chawla R, Jaggi S. Microvasular and macrovascular complications in diabetes mellitus: distinct or continuum? Indian J Endocrinol Metab. 2016;20:546-51.

36. Chaoxin J, Daili S, Yanxin H, Ruwei G, Chenlong W, Yaobin T. The influence of angiotensin-converting enzyme 2 gene polymorphisms on type 2 diabetes mellitus and coronary heart disease. Eur Rev Med Pharmacol Sci. 2013;17:2654-9.

37. Wu YH, Li JY, Wang C, Zhang LM, Qiao H. The ACE2 G8790A polymorphism: involvement in type 2 diabetes mellitus combined with cerebral stroke. J Clin Lab Anal. 2017;31. https://doi.org/10.1002/jcla.22033.

38. Wu X, Zhu B, Zou S, Shi J. The association between ACE2 gene polymorphism and the stroke recurrence in Chinese population. J Stroke Cerebrovasc Dis. 2018. https://doi.org/10.1016/j.jstrokecerebrovasdis.2018.06.001.

39. Kumar A, Rani B, Sharma R, Kaur G, Prasad R, Bahl A, Khullar M. ACE2, CALM3 and TNNI3K polymorphisms as potential disease modifiers in hypertrophic and dilated cardiomyopathies. Mol Cell Biochem. 2018;438:167-74.

40. Feng W, Sun L, Qu XF. Association of AGTR1 and ACE2 gene polymorphisms with structural atrial fibrillation in a Chinese Han population. Pharmazie. 2017;72:17-21.

41. Ni J, Ma KL, Wang CX, Liu J, Zhang Y, Lv LL, Ni HF, Chen YX, Ruan XZ, Liu $B C$. Activation of renin-angiotensin system is involved in dyslipidemiamediated renal injuries in apolipoprotein E knockout mice and HK-2 cells. Lipids Health Dis. 2013;12:49.

42. Chen J, Li D, Schaefer R, Mehta JL. Cross-talk between dyslipidemia and renin-angiotensin system and the role of LOX-1 and MAPK in atherogenesis studies with the combined use of rosuvastatin and candesartan. Atherosclerosis. 2006:184:295-301.

43. Chen YY, Zhang P, Zhou XM, Liu D, Zhong JC, Zhang CJ, Jin LJ, Yu HM. Relationship between genetic variants of ACE2 gene and circulating levels of ACE2 and its metabolites. J Clin Pharm Ther. 2018:43:189-95.

44. Liu D, Chen Y, Zhang P, Zhong J, Jin L, Zhang C, Lin S, Wu S, Yu H. Association between circulating levels of ACE2-Ang-(1-7)-MAS axis and ACE2 gene polymorphisms in hypertensive patients. Medicine (Baltimore). 2016;95:e3876.

45. Yamamoto K, Ohishi M, Katsuya T, Ito N, Ikushima M, Kaibe M, Tatara Y, Shiota A, Sugano S, Takeda S, et al. Deletion of angiotensin-converting enzyme 2 accelerates pressure overload-induced cardiac dysfunction by increasing local angiotensin II. Hypertension. 2006;47:718-26.

46. Rabelo LA, Todiras M, Nunes-Souza V, Qadri F, Szijarto IA, Gollasch M, Penninger JM, Bader M, Santos RA, Alenina N. Genetic deletion of ACE2 
induces vascular dysfunction in C57BL/6 mice: role of nitric oxide imbalance and oxidative stress. PLoS One. 2016;11:e0150255.

47. Yang HY, Lu KC, Fang WH, Lee HS, Wu CC, Huang YH, Lin YF, Kao SY, Lai $\mathrm{CH}$, Chu CM, Su SL. Impact of interaction of cigarette smoking with angiotensin-converting enzyme polymorphisms on end-stage renal disease risk in a Han Chinese population. J Renin-Angiotensin-Aldosterone Syst. 2015;16:203-10

48. Wysocki J, Ye M, Soler MJ, Gurley SB, Xiao HD, Bernstein KE, Coffman TM, Chen S, Batlle D. ACE and ACE2 activity in diabetic mice. Diabetes. 2006;55:2132-9.

\section{Ready to submit your research? Choose BMC and benefit from:}

- fast, convenient online submission

- thorough peer review by experienced researchers in your field

- rapid publication on acceptance

- support for research data, including large and complex data types

- gold Open Access which fosters wider collaboration and increased citations

- maximum visibility for your research: over $100 \mathrm{M}$ website views per year

At $\mathrm{BMC}$, research is always in progress.

Learn more biomedcentral.com/submissions 